\title{
5 Personalised wellbeing planning
}

\author{
Lindsay G. Oades and Aaron Jarden
}

\section{How to use this policy}

Student wellbeing is important, as is academic performance. Moreover, wellbeing and academic performance are related. Through personalised wellbeing planning and coaching, students can enhance both wellbeing and academic performance in the context of a dynamic and challenging world. This policy highlights how schools can utilise the potential learning and wellbeing benefits of personalised planning for wellbeing, while also supporting students to achieve academically. The policy is designed to be used flexibly, by using the three evidence-based principles - personalisation (Lu et al., 2014; Pane et al., 2015), connection and choice (Deci \& Ryan, 2012; Diener, E., Biswas-Diener, R., et al., 2018) - and evidence-based action planning (Hagger \& Luszczynska, 2014). These principles, which have students at the centre, are relevant to the whole school, teachers, parents and caregivers. Furthermore, as personalised wellbeing planning is a process involving collaboration and coaching, it is, by definition, tailored to a student's age, ability and context, and accordingly, sits above various programs operating within the school. Personalised wellbeing planning can be integrated with curriculum, pedagogy and assessment. Importantly, it is recommended that personalised wellbeing planning and coaching fully utilises the offerings afforded by online technology, catalysed by the coronavirus pandemic, particularly to encourage collaboration between students, teachers and parents. When implementing a Personalised Wellbeing Planning policy, it is recommended that it is considered in a staged fashion across several years in order to (a) fully realise the potential of this combination evidence-based principles; (b) become integrated with existing programs; and (c) ensure that it accommodates the wide range of ongoing demands made on school staff.

This policy example is intentionally broad and school policy creators are encouraged to delete and build upon suggestions below to create a policy that best represents their school.

[To adapt and use this policy, delete or modify the text as indicated]

[INSERT name of school] Wellbeing planning policy 


\section{Oades \& Jarden}

\section{Rationale}

In recognition of the importance of student wellbeing and its relationship to academic performance (Adler, 2017; Marques et al., 2011), schools play an important role in assisting students to learn skills to manage their own wellbeing and support the wellbeing of others. To wait until a student deteriorates in their mental wellbeing before referring them to counselling or medical services is old paradigm thinking. Likewise, it is also old paradigm thinking to view learning about wellbeing solely for illness prevention purposes. Wellbeing is important in its own right, and relates to being capable. A new paradigm, aligned with social and emotional learning and positive education, is to equip students with knowledge and skills about and for wellbeing. There is a need to share the responsibility across the community for wellbeing, rather than relying on external professional or, particularly, clinical services. The aim of this policy is to build student, staff and parent skills and capabilities around wellbeing (Seligman et al., 2009) and wellbeing literacy (Oades et al., 2017). However, this policy goes further by seeking to personalise learning by enabling students to be engaged in coaching (Green et al., 2006) and to make personalised plans for their own wellbeing and its close relationship to academic performance. These plans should be personalised to the context of the student (Ciarrochi et al., 2016), relevant to their age, culture, personality, values, personal conceptualisation of wellbeing, motivation, language use about wellbeing, and aspirations. With the assistance of coaches (who may be a range of school staff or, when relevant, an external coach), and in consultation and collaboration with parents or guardians when possible, optimally, a student will set, enact and monitor progress towards their personally chosen goals and activities relevant to their own wellbeing. Optimally, progress towards working on wellbeing-enhancing activities (rather than wellbeing per se) will be reported within academic and other non-curricular activity.

An overarching principle is that the process itself will promote agency of the student, with the key implicit learning that wellbeing itself can be changed and often improved through skills, learning and actions. Such a process enables students to integrate and use generic curriculum for their personal situation.

\section{Purpose}

The purpose of this policy is to support the development and implementation of personalised wellbeing plans for students across the whole of the school community. The policy position offered here is one in which a school representative works together with students and parents to maximise educational outcomes and wellbeing, by supporting students to self-regulate their wellbeing actions and academic actions.

\section{Scope}

This policy applies to school leadership and teaching staff of [INSERT name of school]. It is a shared responsibility between students, staff and parents and 
carers that personalised wellbeing plans are developed with students, enacted by students and monitored by school systems, each year. As such, the development and enactment of this policy and related procedures should take the needs of the whole school community into consideration. This may require some reasonable adjustments and exemptions for individual students or specific teaching and learning contexts.

\section{Policy statement}

Personalised wellbeing planning: [INSERT name of school] aims for all students of our school to have a personalised wellbeing plan, as we value student wellbeing and academic performance. We endorse the three principles regarding student wellbeing and academic performance that underpin personalised wellbeing planning: (1) Personalisation; (2) Connection and Choice; and (3) Evidenced-Based Action Planning. Each of these has a long-standing and strong scientific literature base.

\section{Personalisation}

At [INSERT name of school] students not only learn about wellbeing, they learn about it in a personalised way through planning, action and reflection.

At [INSERT name of school] our approach to personalising wellbeing for students involves considering their personality, social context, values and other individual differences.

We acknowledge that individual understandings of wellbeing can be different from student to student and, as such, so will the goals, activities and strategies used to maintain or increase their wellbeing.

At [INSERT name of school] we strive to use evidence-based resources (books, programs, courses, etc.) that have been shown to work for many people.

Students at [INSERT name of school] are explicitly taught to ask questions about what gives them meaning in their lives.

\section{Connection and choice}

At [INSERT name of school] school leaders and teachers realise the importance of connection in building wellbeing, and that social connections are major drivers of wellbeing.

At [INSERT name of school] we understand that when it comes to wellbeing and performance planning, collaboration - working together towards common goals - helps students to feel connected and supported.

Students and teachers at [INSERT name of school] understand that wellbeing is a shared responsibility, and that supportive, collaborative conversations about and for wellbeing are essential. These collaborative conversations support the choice and autonomy of students, and enable students to think critically about what is most important to them. 


\section{Evidenced-based action planning}

At [INSERT name of school] we realize that it is difficult to experience sustained wellbeing and perform well without taking some planned actions (e.g., exercise, study, trying to make new friends) at some point in the journey.

Students at [INSERT name of school] are encouraged to take actions towards their personalised goals in ways that are consistent with the research about action planning. This includes having tangible actions that are monitored and specific to a context.

At [INSERT name of school] students are taught that wellbeing and performance is most likely to happen and improve when actions are planned, reviewed and supported by a valued other person.

\section{Rating of evidence base}

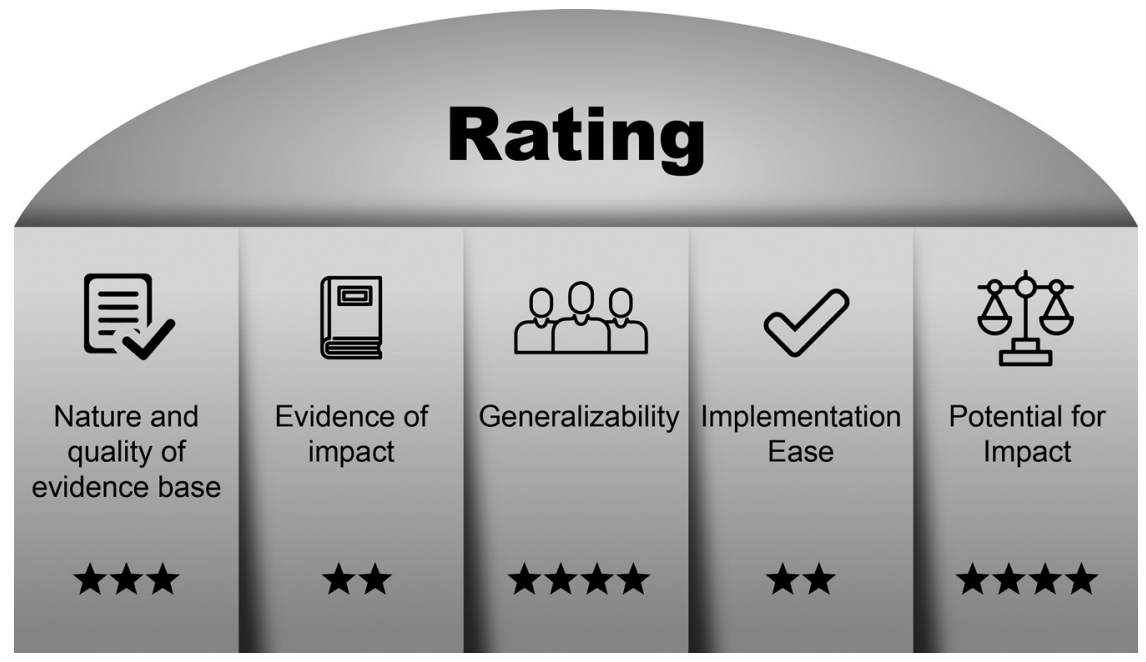

Figure 5.1. Personalised Wellbeing Planning Rating of Evidence.

Author Note. This policy is built from several evidence bases, corresponding to each of the three principles mentioned. Evidence-based action planning as a principle points to ongoing evidence as it is generated. Evidence of impact takes time. This approach is new, hence impact is unfolding now. Because this approach is based on general principles derived from evidence, the generalisability is high. Adaptation to context is essential. Implementation ease depends on the scope and intensity of what is implemented. There are aspects of the principles that can be implemented relatively easily. Full scale programs, coaching and online offerings following through to school reports will require significant resources. The potential impact is significant. If implemented successfully, then significant gains in wellbeing, performance, self-efficacy and parent involvement in student wellbeing and performance can be enhanced. The utilisation also of digital technology will be consolidated. 


\section{Authorship}

Professor Lindsay G. Oades, The University of Melbourne

Associate Professor Aaron Jarden, The University of Melbourne

[INSERT RELEVANT STAFF MEMBERS]

\section{Related policy and documents}

Langford, R., Bonell, C., Jones, H., Pouliou, T., Murphy, S., Waters, E., ... \& Campbell, R. (2015). The World Health Organization's Health Promoting Schools framework: a Cochrane systematic review and meta-analysis. $B M C$ Public Health, 15(1), 130.

\section{Date of ratification}

This policy was ratified on the [INSERT DATE].

\section{Date of review}

This policy will be reviewed by [INSERT DATE].

\section{Further reading}

Norrish, J. M., Williams, P., O'Connor, M., \& Robinson, J. (2013). An applied framework for positive education. International Journal of Wellbeing, 3, 147-161.

Slemp, G. R., Chin, T. C., Kern, M. L., Siokou, C., Loton, D., Oades, L. G., Vella-Brodrick, D. A., \& Waters, L. (2017). Positive education in Australia: Practice, measurement, and future directions. In E. Frydenberg, A. J. Martin, \& R. J. Collie (Eds.), Social and emotional learning in Australia and the Asia Pacific (pp. 101-122). Singapore: Springer.

\section{Expert consultation}

It is recommended that, in addition to consultation with school administration, school teachers, wellbeing staff, parents and students, further consultation by school leadership is made with experts in coaching psychology, medical professionals and information technology experts to assist with building online platforms to assist in developing these personalised wellbeing plans. Training in how to coach and create action plans collaboratively with students is necessary.

\section{References}

Adler, A. (2017). Well-being and academic achievement: Towards a new evidencebased educational paradigm. In M. A. White, G. R. Slemp, \& A. S. Murray (Eds.), Future directions in well-being (pp. 203-208). Cham: Springer. 


\section{Oades \& Jarden}

Ciarrochi, J., Atkins, P. W. B., Hayes, L. L., Sahdra, B. K., \& Parker, P. (2016). Contextual positive psychology: Policy recommendations for implementing positive psychology into schools. Frontiers in Psychology, 7(1561).

Deci, E. L., \& Ryan, R. M. (2012). Self-determination theory. In P. A. M. Van Lange, A. W. Kruglanski, \& E. T. Higgins (Eds.), Handbook of theories of social psychology (pp. 416-436). Thousand Oaks: Sage Publications.

Diener, E., Biswas-Diener, R., et al. (2018). Social well-being: Research and policy recommendations. In J. F. Helliwell, R. Layard, \& J. Sachs (Eds.), Global happiness policy report: 2018 (pp. 129-159). New York: Sustainable Development Solutions Network.

Green, L. S., Oades, L. G., \& Grant, A. M. (2006). Cognitive-behavioural, solutionfocused life coaching: Enhancing goal striving, well-being and hope. Journal of Positive Psychology, 1(3), 142-149.

Hagger, M. S., \& Luszczynska, A. (2014). Implementation intention and action planning Interventions in health contexts: State of the research and proposals for the way forward. Applied Psychology: Health and Well-Being, 6(1), 1-47.

Lu, Y. F., Goldstein, D. B., Angrist, M., \& Cavalleri, G. (2014). Personalized medicine and human genetic diversity. Cold Spring Harbor Perspectives in Medicine, 4(9), a008581.

Marques, S. C., Pais-Ribeiro, J. L., \& Lopez, S. J. (2011). The role of positive psychology constructs in predicting mental health and academic achievement in children and adolescents: A two-year longitudinal study. Journal of Happiness Studies, 12(6), 1049-1062.

Oades, L. G., \& Johnston, A. L. (2017). Wellbeing literacy: The necessary ingredient in positive education. Psychology Behavioural Science International Journal, 3(5), 1-3.

Pane, J. F., Steiner, E. D., Baird, M. D., Hamilton, L. S. (2015). Continued progress, executive summary: Promising evidence on personalized learning - Report. Santa Monica: RAND Foundation.

Seligman, M. E., Ernst, R. M., Gillham, J., Reivich, K., \& Linkins, M. (2009). Positive education: Positive psychology and classroom interventions. Oxford Review of Education, 35(3), 293-311. 